УДК 622.23.05

\author{
АНАЛИЗ ЗАРУБЕЖНОЙ ТЕХНИКИ И ТЕХНОЛОГИИ \\ ЗАКАЧКИ ДИОКСИДА УГЛЕРОДА \\ В НЕФТЕГАЗОНОСТНЫЙ ПЛАСТ. ОБЗОРНАЯ СТАТЬЯ
}

\title{
ANALYSIS OF FOREIGN EQUIPMENT AND TECHNOLOGY OF CARBON DIOXIDE INJECTION INTO THE OIL AND GAS RESERVOIR. REVIEW ARTICLE
}

\section{П.Л. Павлова, Е.И. Михиенкова}

Сибирский федеральный университет, г. Красноярск, Российская Федерация

Praskovya L. Pavlova, Evgeniya I. Mikhienkova,

Siberian Federal University, Krasnoyarsk, Russian Federation

e-mail: ppavlova@sfu-kras.ru

Аннотация. Указом Президента РФ № 666 от 4 ноября 2020 г. необходимо снизить выброс парниковых газов к 2030 году до $70 \%$ относительно уровня 1990 г. на территории РФ. В связи с этим становится актуальным вопрос уменьшения содержания диоксида углерода в атмосфере и углеродного следа промышленных предприятий. Для решения поставленной задачи перспективной технологией является закачка диоксида углерода в пласт с целью увеличения коэффициента извлечения нефти, особенно для месторождений с трудноизвлекаемыми запасами нефти.

В данной статье представлены способы повышения нефтеотдачи, термины и определения, проанализированы мировые исследования и перспективные технологии по закачке диоксида углерода в пласт. Обобщенный анализ техники и технологии закачки диоксида углерода в 
нефтегазоностный пласт имеет практическую значимость для нефтяных и газовых предприятий, проектов, конструкторских и научноисследовательских работ по закачке диоксида углерода в пласт.

Сделаны выводы о необходимости дальнейших исследований по влиянию диоксида углерода на коррозию оборудования и углеродистых сталей, изготовленных по российскому стандарту и применяемых для нефтяной и газовой промышленности, особенно для металлов, используемых для умеренных и холодных климатических условий, а также отмечено, что территория РФ имеет огромный потенциал для хранения жидкого диоксида углерода благодаря климатическим условиям.

Abstract. It is necessary to reduce greenhouse gas emissions by 2030 to $70 \%$ relative to the level of 1990 on the Russian Federation by President Decree of the Russian Federation No. 666 of November 4, 2020. In this regard the issue of reducing the content of carbon dioxide in the atmosphere and the carbon footprint of manufacturing plant becomes urgent. To solve this problem a promising technology is the injection of carbon dioxide into the reservoir in order to increase the oil recovery coefficient, especially for fields with hard-to-recover oil reserves.

This article presents ways to increase oil recovery, terms and definitions, analyzes world research and promising technologies for injecting carbon dioxide into the reservoir. The generalized analysis of the technique and technology of injection of carbon dioxide into the oil and gas reservoir has practical significance for oil and gas industry, projects, design and research works on injection of carbon dioxide into the reservoir.

We are drawn about the need for further research on the effect of carbon dioxide on the corrosion of equipment and carbon steels manufactured according to the Russian standard and used for the oil and gas industry, especially for metals used for moderate and cold climatic conditions, and it is also noted that the Russian Federation has a huge potential for storing liquid carbon dioxide due to climatic conditions. 
Ключевые слова: нефтеотдача; диоксид углерода; технология; техника; закачка

Key words: oil recovery; carbon dioxide; technology; technical equipment; injection

С каждым годом возрастает интерес к методам увеличения нефтеотдачи (МУН) пластов и развиваются научные исследования, направленные на поиски обоснованного подхода к выбору наиболее эффективных технологий разработки месторождений.

Прежде чем рассматривать научные исследования по МУН необходимо разобраться в терминах, принятых в зарубежной нефтяной промышленности.

На этом этапе важно установить разницу между понятиями «повышенная нефтеотдача», далее по тексту EOR (Enhancedoilrecovery), и «улучшенная нефтеотдача», далее IOR (Improvedoilrecovery).

Tермин IOR относится к любому способу повышения нефтеотдачи или передовой технологии добычи нефти, которая реализуется в ходе текущего процесса добычи нефти [25, 39, 58, 70].

Примерами IOR являются технологические методы, приводящие к увеличению добычи нефти, которые используются при первичном, вторичном или третичном способах добычи углеводородов. Например, гидравлический разрыв пласта, кислотная обработка, бурение горизонтальных и дополнительных скважин для уплотнения сетки эксплуатационных скважин [14, 23, 46, 55, 57].

Термин EOR применяется в понятии как «третичный способ добычи», когда в пласт вводятся рабочие жидкости, которые не применяются во вторичном способе добычи нефти (пластовая вода, попутный или природный газ), или для способов и технологий, которые позволяют извлечь остаточную (неподвижную) нефть $[9,37,52,63]$. В то же время методы EOR 
могут применяться после первичной добычи нефти, если обоснованы технико-экономические показатели [13, 40].

В таблице 1 приведены значения коэффициента извлечения нефти для различных методов увеличения нефтеотдачи в мире [40, 61].

Таблица 1. Значения КИН для различных МУН

\begin{tabular}{|c|l|c|}
\hline $\begin{array}{c}\text { Метод увеличения } \\
\text { нефтеотдачи }\end{array}$ & \multicolumn{1}{|c|}{ Технология } & КИН \\
\hline Первичный & $\begin{array}{l}\text { Энергия пласта, использование механизированной } \\
\text { добычи }\end{array}$ & $10-20 \%$ \\
\hline Вторичный & $\begin{array}{l}\text { Поддержание пластового давления за счет закачки } \\
\text { воды и газа }\end{array}$ & $15-30 \%$ \\
\hline Третичный & Способы EOR & $5-15 \%$ \\
\hline
\end{tabular}

На сегодняшний день выделяют четыре метода повышения нефтеотдачи EOR: термический, химический, газовый и микробиологический.

B таблице 2 более подробно приведены способы EOR с их переводом с английского языка и аббревиатурой, которые распространены в зарубежной нефтяной промышленности. Таблица адаптирована и дополнена из обзорной научной статьи [45].

В нефтяной промышленности наибольшее распространение получил способ повышения нефтеотдачи EOR, основанный на закачке диоксида углерода из-за его высокой эффективности вытеснения нефти и стоимости внедрения, а также уменьшения парниковых газов [31, 48, 44].

Существует два типа вытеснения нефти газовыми методами $[5,27]$ :

- смешивающееся вытеснение;

- несмешивающееся вытеснение.

При использовании газовых методов повышения нефтеотдачи одним из главных параметров, влияющих на их эффективность, является минимальное давление смесимости (далее МДС) нефти и закачиваемого в пласт газа. Это давление, при котором наступает полная смесимость нефти 
и газа (давление, при достижении которого начинает реализовываться механизм смешивающегося вытеснения).

Для измерения МДС можно использовать несколько методов. Традиционными методами определения МДС являются вытеснение нефти газом в трубке с насыпной моделью породы (Slimtubetest, STT) [68], метод всплывающего пузырька (Rising Bubble Apparatus, RBA) [15] и метод исследования межфазного натяжения (Vanishing Interfacial Tension, VIT) [47]. Метод с использованием сплывающего пузырька был разработан в начале 1980-х годов и получил признание в качестве эффективного метода измерения МДС.

Также существует корреляционные формулы для расчета МДС [7, 16, 24, 32, 51, 68, 69]. Ошибки при применении корреляционных формул для расчетов МДС могут достигать 15-20\%.

Проводятся работы по разработке метода вычисления МДС за счет использования искусственного интеллекта. В научной работе [26] для прогнозирования МДС диоксида углерода с нефтью использовались искусственная нейронная сеть, радиальная базисная функция, обобщенная нейронная сеть и система нечеткой логики. Полученные результаты сравнили с распространенными методами определения МДС. В результате разработанная модель показала, что средняя абсолютная погрешность вычислений составляет 6,6%, коэффициент корреляции - 0,98. 
Таблица 2. Способы повышения нефтеотдачи

\begin{tabular}{|c|c|c|c|c|c|}
\hline $\begin{array}{c}\text { Способы повышения } \\
\text { нефтеодачи } \\
\text { (EOR) }\end{array}$ & Механизм & Страны & Технология & Преимущества & Недостатки \\
\hline \multicolumn{6}{|c|}{ Термические методы повышения нефтеотдачи (Thermal EOR (TEOR)) } \\
\hline $\begin{array}{l}\text { Добыча с } \\
\text { применением } \\
\text { внутрипластового } \\
\text { горения (ВПГ) } \\
\text { (InSitu Combustion, } \\
\text { ISC) }\end{array}$ & $\begin{array}{l}\text { При постоянном } \\
\text { нагнетании воздуха или } \\
\text { других газовых смесей с } \\
\text { кислородом в составе } \\
\text { поддерживается } \\
\text { постоянный фронт горения } \\
\text { внутри пласта }\end{array}$ & $\begin{array}{l}\text { Индия, } \\
\text { Румыния, } \\
\text { Канада, США. }\end{array}$ & $\begin{array}{l}\checkmark \text { Нагнетание воздуха под высоким } \\
\text { давлением (High Pressure Air Injection, } \\
\text { HPAI). }\end{array}$ & \multirow{4}{*}{$\begin{array}{l}\text { Можно } \\
\text { осуществлять и } \\
\text { при малой } \\
\text { толщине пласта, а } \\
\text { также в } \\
\text { обводненных, } \\
\text { глинистых, } \\
\text { песчаных и } \\
\text { карбонатных } \\
\text { пластах. } \\
\text { Можно сочетать с } \\
\text { другими } \\
\text { способами } \\
\text { добычи нефти. }\end{array}$} & \multirow{4}{*}{$\begin{array}{l}\text { Загрязнение } \\
\text { окружающей среды } \\
\text { за счет выбросов } \\
\text { паров газов. } \\
\text { Сложность контроля } \\
\text { и неравномерность } \\
\text { горения или нагрева } \\
\text { Дорогая стоимость } \\
\text { эксплуатации. }\end{array}$} \\
\hline \multicolumn{4}{|c|}{ Нагнетание пара в пласт } & & \\
\hline $\begin{array}{l}\text { Метод } \\
\text { интенсификации } \\
\text { притока с циклической } \\
\text { закачкой пара }\end{array}$ & $\begin{array}{l}\text { Пар закачивается в } \\
\text { нагнетательные скважины } \\
\text { для вытеснения нефти в } \\
\text { сторону добывающей } \\
\text { скважины }\end{array}$ & $\begin{array}{l}\text { Бразилия, } \\
\text { Венесуэла, } \\
\text { США, Индия, } \\
\text { Тринидад и } \\
\text { Тобаго, } \\
\text { Оман, Китай, } \\
\text { Канада, Россия. }\end{array}$ & \multirow{2}{*}{$\begin{array}{l}\checkmark \text { Парощелочное воздействие на пласт } \\
\text { (ThermalAlcaliInjection, THAI). } \\
\checkmark \text { Быстый парогравитационный дренаж } \\
\text { (Steam Assisted Gravity Drainage, Fast- } \\
\text { SAGD). } \\
\checkmark \text { Закачка неконденсирующегося газа с } \\
\text { паром (Non-CondensableGasNCG- SAGD). } \\
\checkmark \text { Прямоточная генерация пара (Once } \\
\text { Through Steam Generators, OTSG). } \\
\checkmark \text { Повышение нефтеотдачи за счет } \\
\text { солнечной энергии (Solar thermal enhanced } \\
\text { oil recovery, ST-EOR). } \\
\checkmark \text { Газонефтяной гравитационный дренаж } \\
\text { (Gas-Oil Gravity Drainage, GOGD). } \\
\checkmark \text { Газонефтяной гравитационный дренаж с } \\
\text { термическим подогревом (Thermally Аssisted } \\
\text { Gas-Oil Gravity Drainage, TAGOGD). } \\
\checkmark \text { Tретичный гравитационный дренаж } \\
\text { (TertiaryGravityDrainage, TGD). } \\
\checkmark \text { Закачка воздуха под высоким давлением } \\
\text { (High-PressureAirInjection, HPAI). }\end{array}$} & & \\
\hline $\begin{array}{l}\text { Гравитационное } \\
\text { дренирование при } \\
\text { закачке пара } \\
\text { (SAGD) }\end{array}$ & $\begin{array}{l}\text { Нефть нагревается } \\
\text { циркулирующим паром } \\
\text { при температуре, } \\
\text { которая улучшает его } \\
\text { течение }\end{array}$ & $\begin{array}{l}\text { Канада, } \\
\text { Венесуэла. }\end{array}$ & & & \\
\hline
\end{tabular}




\begin{tabular}{|c|c|c|c|c|c|}
\hline $\begin{array}{c}\text { Способы повышения } \\
\text { нефтеотдачи } \\
\text { (EOR) }\end{array}$ & Механизм & Страны & Технология & Преимущества & Недостатки \\
\hline \multicolumn{6}{|c|}{ Химические методы повышения нефтеотдачи (Chemical EOR (CEOR)) } \\
\hline $\begin{array}{l}\text { Полимерное } \\
\text { заводнение }\end{array}$ & $\begin{array}{l}\text { Полимеры закачиваются в } \\
\text { пласт, а затем в воду }\end{array}$ & $\begin{array}{l}\text { Бразилия, } \\
\text { Китай, Оман, }\end{array}$ & \multirow{5}{*}{$\begin{array}{l}\checkmark \text { Синтетические полимеры } \\
\text { (syntheticpolymers (т. е. полиакриламид или } \\
\text { PAM). } \\
\checkmark \quad \text { Гидролизованный полиакриламид } \\
\text { (hydrolysedpolyacrylamide (HРAM)). } \\
\checkmark \quad \text { Биополимеры ксантановой камеди } \\
\text { (biopolymersxanthangum, HРAM-AMPS). } \\
\checkmark \quad \text { Суперабсорбирующий полимерный } \\
\text { композит (superabsorbentpolymercomposite, } \\
\text { SAPc). }\end{array}$} & \multirow{5}{*}{$\begin{array}{l}\text { Недорогие } \\
\text { процессы. } \\
\text { Возможности для } \\
\text { увеличения } \\
\text { добычи нефти. }\end{array}$} & \multirow{5}{*}{$\begin{array}{l}\text { Высокая склонность } \\
\text { к химической } \\
\text { несовместимости. } \\
\text { Проблемы с } \\
\text { установлением } \\
\text { контакта с пластовой } \\
\text { нефтью. }\end{array}$} \\
\hline $\begin{array}{l}\text { ПАВ- } \\
\text { полимерноезаводнение } \\
\text { (SP flooding) }\end{array}$ & $\begin{array}{l}\text { Одновременно в пласт } \\
\text { закачивают ПАВ и } \\
\text { полимеры }\end{array}$ & $\begin{array}{l}\text { Канада, } \\
\text { Суринам, } \\
\text { Мексика, } \\
\text { Аргентина, } \\
\text { Австрия, США, } \\
\text { Индия. }\end{array}$ & & & \\
\hline $\begin{array}{l}\text { Заводнение } \\
\text { растворами } \\
\text { поверхностно- } \\
\text { активных веществ }\end{array}$ & \multirow{3}{*}{$\begin{array}{l}\text { Водные растворы } \\
\text { полимеров, ПАВ и } \\
\text { щелочей закачивают в } \\
\text { пласт }\end{array}$} & $\begin{array}{l}\text { Индонезия, } \\
\text { Бахрейн, США. }\end{array}$ & & & \\
\hline Щелочное заводнение & & $\begin{array}{l}\text { Венгрия, Индия, } \\
\text { США, Россия. }\end{array}$ & & & \\
\hline $\begin{array}{l}\text { Закачка полимерно- } \\
\text { щелочного ПАВ (ASP) }\end{array}$ & & $\begin{array}{l}\text { Китай, США, } \\
\text { Индия, } \\
\text { Венесуэла. }\end{array}$ & & & \\
\hline \multicolumn{6}{|c|}{ Газовые методы повышения нефтеотдачи (Gas EOR (GEOR)) } \\
\hline $\begin{array}{l}\text { Смешивающееся } \\
\text { вытеснение }\end{array}$ & \begin{tabular}{|l|} 
Закачка газа $\left(\mathrm{CO}_{2}\right.$, \\
инертных газов $)$ \\
выполняется для \\
достижения \\
смешиваемости с нефтью \\
при давлениях, равных или \\
превышающих \\
минимальное давление \\
смесимости \\
(minimummiscibilitypressure \\
$($ MМР))
\end{tabular} & $\begin{array}{l}\mathrm{CO}_{2}-\text { США, } \\
\text { Канада. } \\
\mathrm{N}_{2}-\text { США, } \\
\text { Мексика. } \\
\text { Углеводородные } \\
\text { газы - США, } \\
\text { Венесуэла, } \\
\text { Ливия, Канада. }\end{array}$ & $\begin{array}{l}\checkmark \text { Чередующаяся закачка воды и газа } \\
\text { (wateralternatinggas, WAG). } \\
\checkmark \text { Одновременная закачка воды поочередно } \\
\text { с газом } \\
\text { (simultaneouswateralternategasinjection, } \\
\text { SWAG). } \\
\checkmark \quad \text { Полимерная закачка воды поочередно с } \\
\text { газом (роlуmеrwateralternategasPWAG). } \\
\checkmark \quad \text { газовый гравитационный дренаж (gas- } \\
\text { assisted gravity drainage, GAGD). }\end{array}$ & $\begin{array}{l}\text { Дополнительно } \\
\text { добытая нефть } \\
\text { превышает } \\
\text { затраты на } \\
\text { внедрение. } \\
\text { Дополнительное } \\
\text { извлечение } \\
\text { неподвижной } \\
\text { нефти, особенно } \\
\text { за счет закачки } \\
\mathrm{CO}_{2} .\end{array}$ & $\begin{array}{l}\text { Неконтролируемость } \\
\text { процессов в пласте. } \\
\text { Ограниченные } \\
\text { источники газа и } \\
\text { проблемы их } \\
\text { разделения. }\end{array}$ \\
\hline
\end{tabular}




\begin{tabular}{|c|c|c|c|c|c|}
\hline \begin{tabular}{|c|} 
Способы повышения \\
нефтеотдачи \\
(EOR)
\end{tabular} & Механизм & Страны & Технология & Преимущества & Недостатки \\
\hline $\begin{array}{l}\text { Несмешивающееся } \\
\text { вытеснение }\end{array}$ & $\begin{array}{l}\text { Закачка газа }\left(\mathrm{N}_{2}, \mathrm{CO}_{2} \text { и }\right. \\
\text { Т.д.) до минимального } \\
\text { давления смешиваемости }\end{array}$ & & & $\begin{array}{l}\text { Уменьшение } \\
\text { парниковых газов } \\
\text { из окружающей } \\
\text { среды. }\end{array}$ & \\
\hline \multicolumn{6}{|c|}{ Микробиологические методы повышения нефтеотдачи(MicrobialEOR (MEOR)) } \\
\hline Микробиологическое & $\begin{array}{l}\text { Закачка микроорганизмов } \\
\text { в пласт с целью } \\
\text { повышения нефтеотдачи }\end{array}$ & \begin{tabular}{|l|} 
Малайзия, \\
Индия, Россия, \\
Австралия, \\
Тринидад- \\
Тобаго, Китай, \\
Германия; \\
Норвегия, \\
Саудовская \\
Аравия \\
Польша Канада \\
Оман \\
США \\
Румыния \\
Венгрия \\
Бывшая \\
Чехословакия
\end{tabular} & $\begin{array}{l}\checkmark \text { Введение адаптированных обогащенных } \\
\text { смешанных культур } \\
\text { (daptedmixedenrichmentcultures, AMEC). } \\
\checkmark \text { селективное закупоривание, стимуляция } \\
\text { местной микробиоты, генетически } \\
\text { модифицированные микроорганизмы, } \\
\text { ферментативное повышение нефтеотдачи } \\
\text { пластов (enzyme EOR, EEOR) }\end{array}$ & $\begin{array}{l}\text { Низкие } \\
\text { эксплуатационные } \\
\text { расходы. } \\
\text { Экологичность. }\end{array}$ & $\begin{array}{l}\text { Медленная и низкая } \\
\text { нефтеотдача. } \\
\text { Требует сложные и } \\
\text { дополнительные } \\
\text { процедуры. }\end{array}$ \\
\hline
\end{tabular}




\section{Смешивающеея вытеснение нефти}

Для проектов закачки $\mathrm{CO}_{2}$ известно, что $\mathrm{MДC} \mathrm{CO}_{2}$ и пластового флюида (нефти) зависит от чистоты $\mathrm{CO}_{2}$, состава нефти, давления и температуры пласта. Присутствие $\mathrm{H}_{2} \mathrm{~S}, \mathrm{C}_{2} \mathrm{H}_{6}$ или промежуточных углеводородов (таких как $\mathrm{C}_{3}, \mathrm{C}_{4}$ ) может уменьшить МДС $\mathrm{CO}_{2}$, в то время как присутствие $\mathrm{CH}_{4}$ или

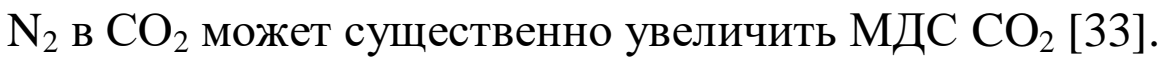

Было отмечено, что на МДС дополнительно влияет молекулярная масса сырой нефти [6]. В итоге для определения МДС рекомендуется определить состав сырой нефти. Высокая концентрация легких компонентов в сырой нефти увеличивает МДС, в то время как более высокая концентрация промежуточных компонентов снижает МДС [19, 68]. Экспериментальные исследования $[41,68]$ показали, что присутствие азота в двуокиси углерода отрицательно влияет на добычу нефти, и что увеличение концентрации азота до 30 \% может привести к потере 10 \% добываемой нефти.

Азот, выделяемый из дымовых и выхлопных газов и $\mathrm{CH}_{4}$ из повторно закаченного $\mathrm{CO}_{2}$, будут наиболее вероятными загрязнителями закачиваемого в пласт диоксида углерода.

В научной работе [18] проведено экспериментальное исследование по определению МДС нефти и чистого $\mathrm{CO}_{2}$, а также нефти и загрязненного $\mathrm{CO}_{2}$. В качестве загрязнителей диоксида углерода выступали $\mathrm{N}_{2}$ и $\mathrm{CH}_{4}$. Для прогнозирования и сравнения МДС нечистого $\mathrm{CO}_{2}$ и нефти использовались корреляции [7] и [51]. Образец нефти для экспериментальных исследований был взят из месторождения Enyana Corporation в Уэйберне на юго-востоке Саскачевана вблизи города Вейберн (Канада), где осуществляется проект по закачке $\mathrm{CO}_{2}$.

Экспериментальное исследование показало, что для данной нефти перспективными методами повышения нефтеотдачи EOR (с МДС ниже $80 \%$ давления разрыва пласта) являются чистый $\mathrm{CO}_{2}$ и смешанный $\mathrm{CO}_{2}$, содержащий примерно $12 \% \mathrm{CH}_{4}$ или $5 \% \mathrm{~N}_{2}$. 
В научной работе [62] оценен потенциал смесей $\mathrm{N}_{2}, \mathrm{CO}_{2}$ и $\mathrm{N}_{2}-\mathrm{CO}_{2}$ для повышения нефтеотдачи вместе со временем прорыва газов. Результаты работы показали, что чистый газ $\mathrm{CO}_{2}$ имеет самую высокую степень извлечения нефти из образца породы, затем следует смесь $\mathrm{N}_{2}-\mathrm{CO}_{2}$, а газ $\mathrm{N}_{2}$ имеет самую низкую степень извлечения. Результаты анализа времени прорыва газа показали, что смесь $\mathrm{N}_{2}-\mathrm{CO}_{2}$ имела самое длительное время прорыва, $\mathrm{N}_{2}$ - самое короткое время прорыва, а $\mathrm{CO}_{2}$ - более длительное время прорыва, в отличие от чистого газа $\mathrm{N}_{2}$. Это связано с тем, что $\mathrm{N}_{2}$ обладает очень низкой адсорбционной способностью и, следовательно, быстро проходит через образец породы. $\mathrm{CO}_{2}$ обладает более высокой адсорбционной способностью и, следовательно, проходит намного дольше через образец породы.

На основе технологии закачки $\mathrm{CO}_{2}$ были исследованы три схемы закачка диоксида углерода и азота: закачка смешанного газа $\mathrm{CO}_{2}$, закачка $\mathrm{CO}_{2} \mathrm{c}$ чередованием $\mathrm{N}_{2}(\mathrm{CAN})$ и закачка $\mathrm{N}_{2}$ с чередованием $\mathrm{CO}_{2}(\mathrm{NAC})$, также был проведен сравнительный анализ распределения давления, молярной доли $\mathrm{CO}_{2}$ [64]. Основываясь на экспериментальных результатах, авторы работы установили, что процесс закачки $\mathrm{CO}_{2}$ с чередованием $\mathrm{N}_{2}$ является наилучшим по сравнению с представленными способами. Параметрический анализ показал, что наиболее важным фактором является скорость закачки газа азота. Кроме этого, в научной работе подробно исследовано влияние гравитационного дренажа, проницаемости коллектора, природы трещин и неоднородности проницаемости на добычу нефти в процессе закачки. Данные результаты показывают, что плотный нефтяной пласт с лучшей вертикальной связностью, плохим ростом трещин и более высокой неоднородностью является оптимальным для процесса закачки диоксида углерода и азота.

Авторы работы [35] предлагают снизить давление смесимости $\mathrm{CO}_{2}$ и сырой нефти за счет использования алканов, спиртов, ПАВ и петролейного эфира (нефтяного эфира). Экспериментальные исследования показали, что 
петролейный эфир с диапазоном кипения 30-60 ${ }^{\circ} \mathrm{C}$ уменьшает МДС в системе « $\mathrm{CO}_{2}$ - нефть» на 6,19 МПа, т.е. на 12,17 \%. В научном исследовании [44] показано, что присутствие $\mathrm{C}_{5}+$ также снижает МДС с 23,7 до 19,8 МПа.

В целом теоретические и экспериментальные исследования показывают, что диоксид углерода является наилучшим газом для закачки его в нефтяной пласт. В лабораторных условиях, при неограниченной смесимости, коэффициент вытеснения нефти диоксидом углерода может достигать 98$99 \%$.

МДС для чистого диоксида углерода с пластовой нефтью в зависимости от температуры варьируется в диапазоне от 15 до 25 МПа. Примеси, присутствующие в диоксиде углерода, например, закачка совместно с водой и/или попутным газом, увеличивают МДС до 30-40 МПа и более. В результате можно сказать, что область применения смешивающегося вытеснения газом с примесями перспективно для глубокозалегающий легких нефтей с низкопроницаемыми коллекторами. Но также экспериментальные исследования показывают, что МДС можно снизить за счет применения алканов, спиртов, ПАВ и петролейного эфира (нефтяного эфира).

\section{Несмешивающееся вытеснение нефти}

Для несмешивающегося вытеснения нефти газом давление в пласте должно быть ниже МДС. Можно сказать, что закачка несмешивающегося газа впервые использовалась для поддержания пластового давления. На данный момент его выделяют как один способ повышения нефтеотдача EOR за счет применения диоксида углерода, азота и газов, выделяемых источниками загрязнения окружающей среды (дымовых газов).

Несмешивающийся газ обычно закачивают поочередно с водой. Для осуществления закачки газа требуется использование компрессоров высокого давления. 
При закачке несмешивающегося газа в пласт, одним из важных параметров, происходящих между газом и нефтью, является растворимость. Параметр растворимости показывает способность вещества образовывать с другими веществами однородные системы. Например, в процессе растворимости $\mathrm{CO}_{2}$ будет диффундировать с частицами нефти, и в результате нефть набухает [65-67].

Разные нефти будут иметь различную растворимость в зависимости от их состава и свойств, таких как плотность и молекулярная масса [28, 53]. Другим важным параметром, который влияет на растворимость $\mathrm{CO}_{2}$ в пластовой нефти, является термодинамическое условие пласта. Увеличение давления закачки $\mathrm{CO}_{2}$ приводит к повышению растворимости, в то время как повышение температуры - к снижению растворимости. Это объясняется тем, что молекулы $\mathrm{CO}_{2}$ обладают более высокой активностью при высоких температурах $[59,60]$. Растворимость будет наблюдаться при закачке как смешивающегося, так и несмешивающегося вытеснения, но с основным отличием: во время закачки смешивающегося вытеснения межфазное натяжение между нефтью и $\mathrm{CO}_{2}$ станет нулевым [29, 62]. При несмешивающейся закачке $\mathrm{CO}_{2}$ повышается его растворимость в нефти. Данное явление можно использовать для повышения нефтеотдачи пластов с высоковязкими нефтями $[17,21]$.

В результате растворения $\mathrm{CO}_{2}$ в нефти, нефть получает положительные характеристики, такие как более низкая вязкость, более высокая относительная проницаемость и больший объем (набухание). Для того чтобы измерить степень набухания сырой нефти, разработано несколько экспериментальных методов. Большинство экспериментов по исследованию набухания нефти проводятся с прозрачной визуализацией, где можно увидеть явление набухания. Наиболее широко используются эксперименты по визуализации потока и удельной площади поверхности раздела фаз [8, 56]. Также проводятся эксперименты по заводнению активной зоны для изучения способности несмешивающегося $\mathrm{CO}_{2}$ 
увеличивать добычу нефти [50]. Ведутся экспериментальные исследования по несмешивающейся закачке $\mathrm{CO}_{2}$ с другими веществами, такими как вода и пар $[6,10,71]$.

Давление закачки $\mathrm{CO}_{2}$ и температура пласта являются двумя важными факторами, которые влияют на растворение $\mathrm{CO}_{2}$ в нефти, а также на набухание нефти. Следовательно, они влияют на производительность процесса закачки несмешивающегося $\mathrm{CO}_{2}$. По мере повышения температуры пласта растворимость $\mathrm{CO}_{2}$ в нефти будет уменьшаться из-за увеличения активности молекул газа, что приводит к тенденции высвобождения молекул из раствора. В результате $\mathrm{CO}_{2}$ не растворяется в нефти [6, 42]. Данное снижение растворимости приведет к снижению набухания нефти, что, в свою очередь, становится причиной снижения извлечения нефти из-за уменьшения взаимодействия $\mathrm{CO}_{2}$ с нефтью. С другой стороны, увеличение давления закачки $\mathrm{CO}_{2}$ приводит к увеличению растворимости $\mathrm{CO}_{2}$ и, следовательно, к увеличению взаимодействия $\mathrm{CO}_{2}$ с нефтью. Это связано с тем, что молекулы газа сжимаются в меньший объем и, следовательно, будут стремиться растворяться в нефти. Повышение давления до высокого значения в конечном итоге приведет к тому, что $\mathrm{CO}_{2}$ станет смешиваться с нефтью [20, 43]. Поэтому для несмешивающейся закачки $\mathrm{CO}_{2}$ более благоприятна низкая температура пласта и более высокое давление закачки $\mathrm{CO}_{2}$.

Результаты моделирования нефтяных пластов показали, что для пластов с тяжелой нефтью применение смешиваемого вытеснения является трудоемким процессом, поэтому рекомендуется использовать несмешиваемую закачку.

\section{Техника и технология закачки диоксида углерода в пласт}

В научной литературе можно встретить термин «huff-n-puffprocess», что обозначает циклическую закачку воды и газа.

Циклическая (чередующаяся) закачка воды и газа (WAG) - это хорошо изученный метод EOR и IOR, имеющий успешные результаты в 
лабораторных исследованиях и производственных проектах. Из-за доказанной эффективности различные варианты WAG-технологий внедрены в производство в таких странах как США, Канада, Мексика и Венесуэла. Для улучшения производственных характеристик циклической закачки воды и газа изменяют соотношение количества жидкой и газовой фаз, условий его эксплуатации.

В итоге появились альтернативные технологии, такие как закачивание пены (FAWAG), одновременная закачка воды и газа (карбонизированная вода) (SWAG), циклическая закачка полимеров и газа (PAG), полимерное заводнение (PAWAG) и циклическая закачка воды с воздухом высокого давления (WAHPAI).

Авторы работы [59] предлагают квалифицировать WAG-технологию по технологическому процессу и по применяемому флюиду, что на наш взгляд отражают все разнообразие циклической закачки воды и газа (рисунок 1).

Калифорнийская компания UnionOil (UNOCAL) впервые представила гибридную технологию закачки $\mathrm{CO}_{2}$ и закачки WAG. В данной технологии вводится значительный объем $\mathrm{CO}_{2}$, за которым следует циклическая закачка воды и газа в соотношении 1:1. При одновременной закачке воды и газа (SWAG), газ и вода смешиваются на поверхности и закачиваются в пласт.

Применение $\mathrm{CO}_{2}$ для увеличения нефтеотдачи пластов не предъявляет особых требований к системе разработки месторождения, но технология заводнения обязательно должна быть внутриконтурная, либо должны применяться различные модификации площадного заводнения. Предпочтение должно быть отдано активным, т.е. малорядным системам разработки месторождений.

Для несмешивающейся закачки $\mathrm{CO}_{2}$ рекомендуется применять циклическую закачку воды и газа.

Примерная технологическая схема для циклической закачки воды и газа показана на рисунке 2 [38]. 


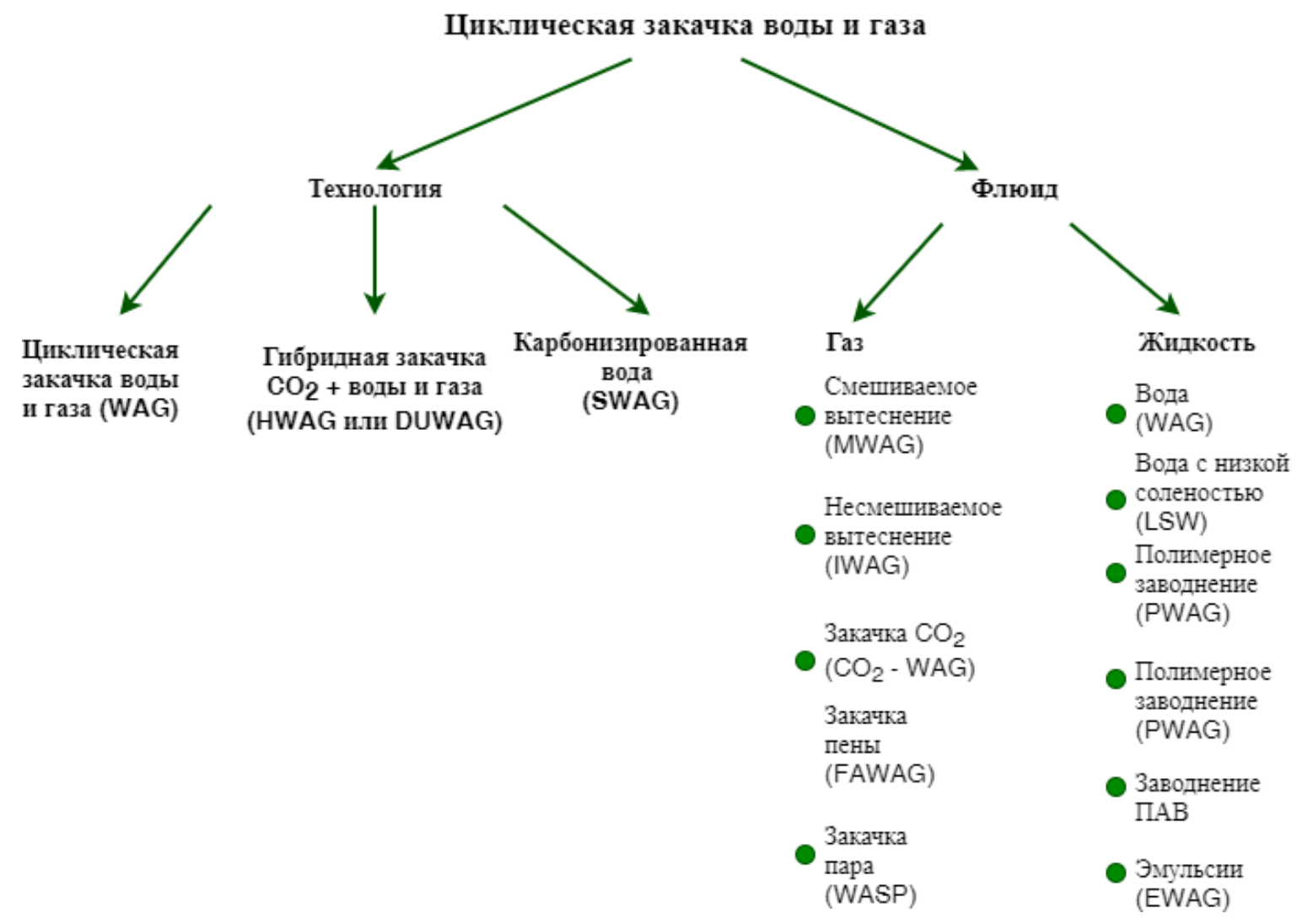

Рисунок 1. Классификация циклической закачки воды и газа (WAG-технологии)

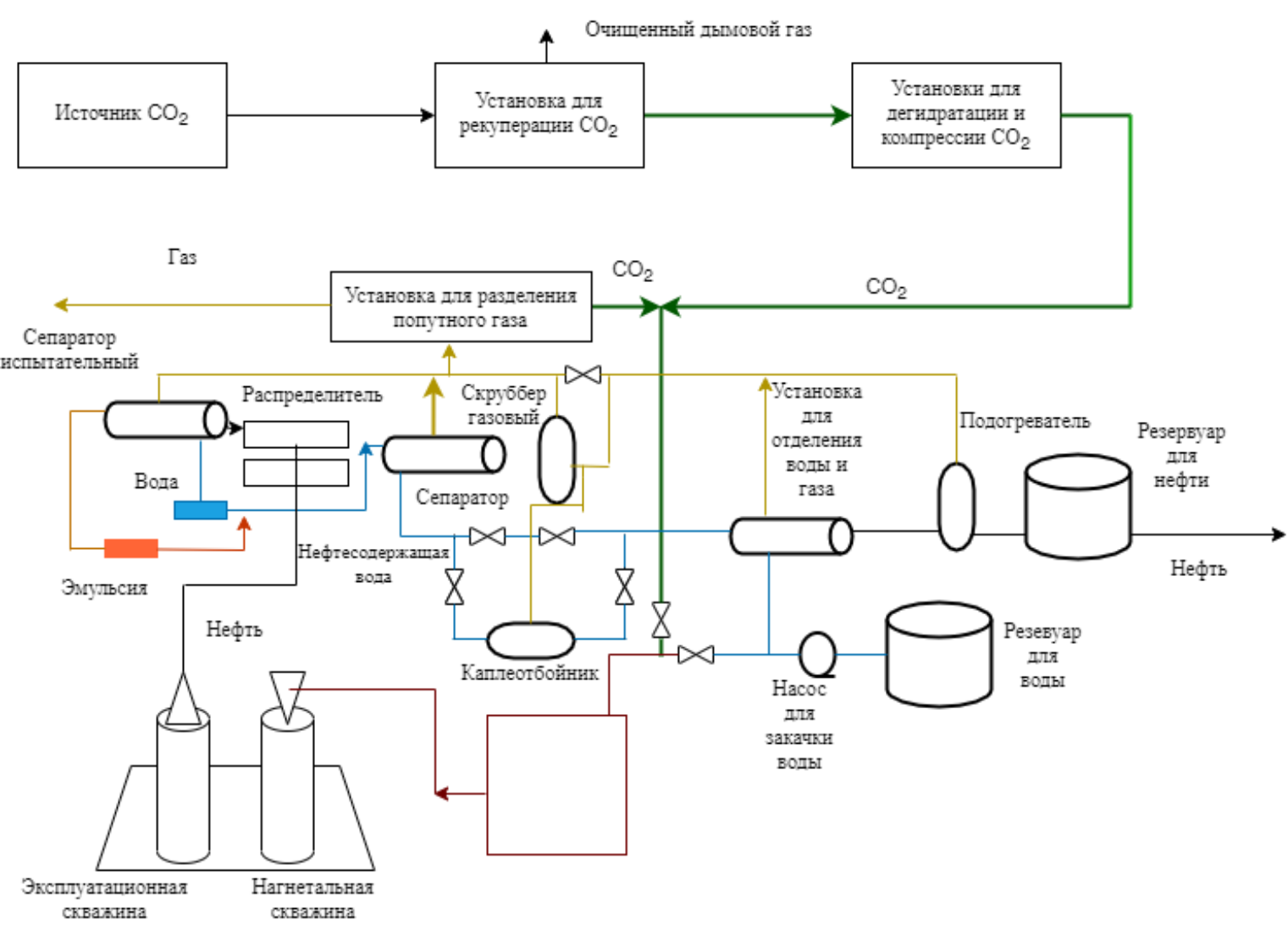

Рисунок 2. Технологическая схема для WAG-технологии 
Транспортировка $\mathrm{CO}_{2}$ является ключевым фактором, который следует учитывать в проекте по закачке $\mathrm{CO}_{2}$. Диоксид углерода может транспортироваться в различных состояниях, но однофазное состояние предпочтительно в трубопроводе по требованиям безопасности. Обычно выбирается сверхкритическая фаза или газовая фаза, т.к. требуется меньше энергии для транспортировки диоксида углерода на большие расстояния. Как правило, давление транспортировки $\mathrm{CO}_{2}$ по трубопроводу находится в диапазоне от 5 до 20 МПа. Транспортировка $\mathrm{CO}_{2}$ грузовыми автомобилями или железнодорожными вагонами может считаться неэффективной и дорогостоящей, если источник его получения находится далеко от места закачки [2]. Более того, проекты по закачке $\mathrm{CO}_{2}-\mathrm{EOR}$ требует миллионов и миллиардов тонн $\mathrm{CO}_{2}$, такие методы транспортировки могут быть непрактичны. В большинстве проектов США $\mathrm{CO}_{2}$ транспортируется по трубопроводной системе в виде сухого газа.

На наш взгляд, транспортировка диоксида углерода по трубопроводной системе на территории России может быть экономически нецелесообразно, так как месторождения находятся далеко от производственных объектов. Возможно, целесообразно строительство автономных станций с установкой стационарных резервуаров.

Диоксид углерода может храниться в жидком виде при температуре приблизительно минус 18 - минус $24{ }^{\circ} \mathrm{C}$ и давлении 1,5-2,0 МПа. Данные параметры могут быть достигнуты за счет использования холодильной установки, состоящей из установленных на полозьях компрессоров и конденсаторов хладагента, а также альтернативой данным системам могут быть термостабилизаторы с принудительной циркуляцией в летнее время. На сегодняшний день термостабилизаторы применяют для охлаждения фундаментов резервуаров с нефтью на северных месторождениях, например на Ванкорском месторождении. Система охлаждения при добавлении изоляции может минимизировать эксплуатационные затраты и уменьшить потери диоксида углерода, возникающие в результате его испарения из-за 
разности давлений и температуры, например при течении через предохранительные клапаны. Газ $\mathrm{CO}_{2}$ обезвоживается, когда его точка росы понижается до температуры ниже $0{ }^{\circ} \mathrm{C}$, и сжимается до критического давления перед подачей в резервуары [4].

В зарубежных проектах $\mathrm{CO}_{2}$ распределяется по всей системе и сооружениям в виде сухого газа через систему магистральных трубопроводов $[4,30]$ из углеродистых сталей. Опыт закачки $\mathrm{CO}_{2}$ показал, что опасности коррозии технологического оборудования нет, если давление закачки устанавливается на уровне 12,4-16,5 МПа (1800-2400 psi) [30]. Однако следует принять меры предосторожности при размещении клапанов. Рекомендуется клапан закреплять на уровне земли, чтобы избежать протечек и образования сухого льда, если он разгерметизируется. Для удаления избыточных примесей $\mathrm{CO}_{2}$ в трубопроводе устанавливают продувочные устройства.

Особое внимание следует уделить фонтанной арматуре, если применяется метод циклической закачки воды и газа (WAG). Если поочередно закачивать воду и $\mathrm{CO}_{2}$, часть системы будет уязвима к коррозии, так как $\mathrm{CO}_{2}$ под высоким давлением взаимодействует с водой и образует кислый раствор [34].

Для уменьшения коррозии технологического оборудования рекомендуется применение коррозионностойких материалов и ингибиторов коррозии. Авторы работы [36] также предлагают уменьшить концентрацию воды, замедлить скорость потока и сократить время контакта для систем транспортировки и закачки $\mathrm{CO}_{2}$, что может смягчить коррозию углеродистых сталей. Для нефтедобывающего оборудования рекомендуется увеличить скорость уноса воды, турбулентность потока и смягчить коррозионную среду.

Авторами работы [54] обобщены результаты зарубежного практического опыта по закачке диоксида углерода и даны рекомендации 
по уменьшению коррозии оборудования. Рекомендуемые материалы для применения по закачке диоксида углерода представлены в виде таблицы 3.

Таблица 3. Материалы конструкций по применению $\mathrm{CO}_{2}$

\begin{tabular}{|c|c|}
\hline Конструкция & Материал \\
\hline $\begin{array}{l}\text { Измерительные участки } \\
\text { трубопровода }\end{array}$ & 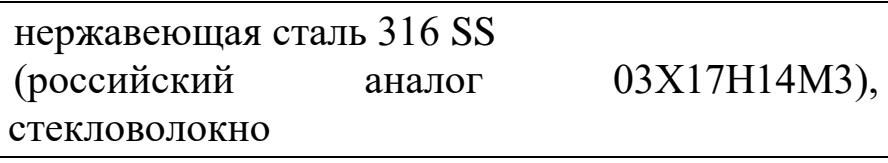 \\
\hline Фонтанная арматура (облицовка) & 316 SS, никель, монель-металл \\
\hline Упаковка и уплотнения клапанов & тефлон, нейлон \\
\hline Устье скважины (облицовка) & 316 SS, никель, монель-металл \\
\hline $\begin{array}{l}\text { Подвеска насосно-компрессорной } \\
\text { трубы }\end{array}$ & 316 SS, Сплав Incoloy \\
\hline Насосно-компрессорные трубы & 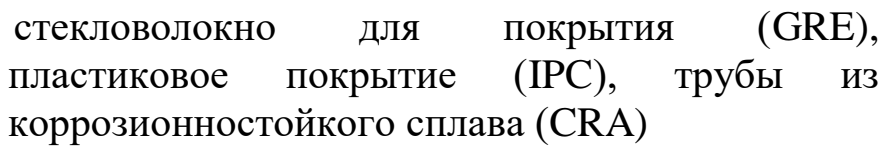 \\
\hline Соединение НКТ & $\begin{array}{l}\text { уплотнительные кольца из GRE, IPC покрытие } \\
\text { резьбы и муфты }\end{array}$ \\
\hline Разъединительный переводник & $\begin{array}{l}\text { Никелевое покрытие контактирующих частей, } \\
\text { нержавеющая сталь } 316 \mathrm{SS}\end{array}$ \\
\hline Пакеры & $\begin{array}{l}\text { Закаленная резина с внутренним покрытием, } \\
\text { никелевое покрытие контактирующих частей }\end{array}$ \\
\hline Цементы и цементные добавки & $\begin{array}{lccc}\text { Цементы } & \text { API } & \text { и/или } & \text { специальные } \\
\text { кислотостойкие цементы и добавки }\end{array}$ \\
\hline
\end{tabular}

Зарубежный практический опыт показал, что при соблюдении мер по смягчению последствий коррозии углеродистая сталь может безопасно и эффективно применяться для обсадных и насосно-компрессорных труб. По оценкам [54] средний срок эксплуатации скважин с закачкой диоксида углерода составит 20-25 лет и более, что сопоставимо с другими нефтяными и газовыми скважинами.

Насосно-компрессорные трубы, которые подвержены воздействию диоксида углерода, насыщенного водой, рекомендуется покрывать пластиком или устанавливать эпоксидные вкладыши из стекловолокна [22, 54]. 
Следует отметить, что на российском рынке производятся насоснокомпрессорные трубы из стеклопластика, которые могут быть применены для закачки $\mathrm{CO}_{2}$ в пласт.

Например, ООО «Бийский завод стеклопластиков» выпускает стеклопластиковые НКТ с внутренним диаметром 63 мм и длиной 9000 мм, на концах которых закреплены металлические головки с поверхностной резьбовой частью.

Если говорить о реализованных проектах по закачке $\mathrm{CO}_{2}$, то в научной статье $[2,49]$ сообщается о пилотном проекте по закачке чистого диоксида углерода (99,9 \%) для повышения нефтеотдачи на месторождении Румайта (Rumaitha), расположенном к северо-востоку от месторождения Баб (Abu Dhabi Co. for Onshore Oil Operations (ADCO)) (рисунок 3). Реализованная технологическая схема показана на рисунке 3.

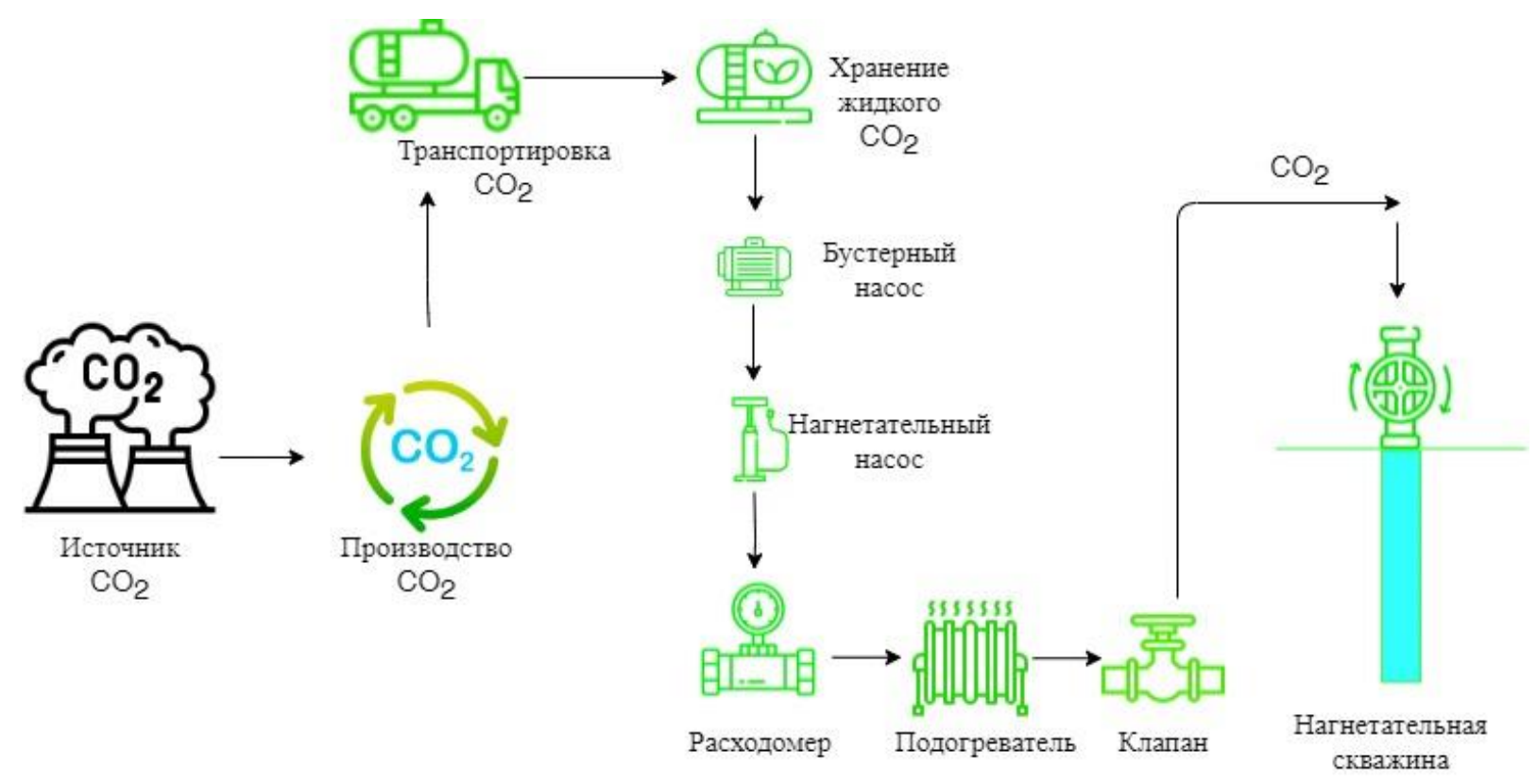

Рисунок 3. Технологическая схема закачки диоксида углерода на месторождении Румайта (Rumaitha)

Основные параметры для нагнетательной и эксплуатационной скважин в проекте по закачке $\mathrm{CO}_{2}$ приведены в таблицах 4 и 5. 
Таблица 4. Основные параметры для нагнетательной скважины $\mathrm{CO}_{2}$

\begin{tabular}{|l|c|c|}
\hline \multicolumn{1}{|c|}{ Параметр } & Значение & Ед. измерения \\
\hline Расход $\mathrm{CO}_{2}$ & 60 & т/сут. \\
\hline Давление закачки & 22,75 & МПа \\
\hline Температура закачки & 35 & ${ }^{\circ} \mathrm{C}$ \\
\hline
\end{tabular}

Таблица 5. Основные параметры для эксплуатационной скважины и связанных с ней объектов

\begin{tabular}{|l|c|c|}
\hline \multicolumn{1}{|c|}{ Параметр } & Значение & Ед. измерения \\
\hline Расход нефти & от 500 до 1500 & баррелей в сут. \\
\hline Расход газа & до 0,04 & $\mathrm{~m}^{3} /$ сут. \\
\hline Давление закрытия устья скважины & 20,68 & $\mathrm{MПа}$ \\
\hline Давление на устье скважины & от 3,45 до 10,34 & $\mathrm{MПа}$ \\
\hline Температура на устье скважины & от 30 до 80 & ${ }^{\circ} \mathrm{C}$ \\
\hline
\end{tabular}

Пилотный проект длился один год с 9 ноября 2009 г. и был успешно завершен. В ходе реализации проекта проведены экспериментальные исследования, разработана и отработана технология по закачке $\mathrm{CO}_{2}$. Компания ADNOC c 2021 г. намерена постепенно увеличивать использование $\mathrm{CO}_{2}$, рассчитывая достичь 7,1 млн м³/сут. к 2027 г. за счет улавливания дополнительного $\mathrm{CO}_{2}$ со своих газоперерабатывающих заводов и закачки его в различные нефтяные месторождения на суше.

\section{Выводы}

В ходе анализа техники и технологии закачки диоксида углерода в нефтегазоностный пласт можно сказать, что данный метод является наиболее изученной и перспективной технологией для дополнительного извлечения нефти. Предпочтительным является смешивающееся вытеснение с целью максимального извлечения нефти, когда давление выше минимального давления смесимости. Но для высоковязкой и тяжелой нефти рекомендуется несмешивающееся вытеснение, когда важным параметром 
является растворимость, и давление не достигает минимального давления смесимости.

Закачка диоксида углерода может производиться в виде непрерывного потока газа или жидкости, либо в виде циклической (чередующейся) закачки воды и газа, известного в мире как WAG. На сегодняшний день существуют разнообразные виды циклической (чередующейся) закачки воды и газа, такие как закачивание пены (FAWAG), одновременная закачка воды и газа (карбонизированная вода) (SWAG), циклическая закачка полимеров и газа (PAG), полимерное заводнение (PAWAG) и циклическая закачка воды с воздухом высокого давления (WAHPAI). Данные технологии можно совместно использовать с диоксидом углерода для увеличения коэффициента извлечения нефти.

Для проектов по закачке диоксида углерода в пласт необходимо уделить особое внимание вопросу его транспортировки до месторождения, особенно для территории РФ. Как мы считаем, территория РФ имеет огромный потенциал для хранения жидкого диоксида углерода благодаря климатическим условиям.

Необходимо рассмотреть вопросы коррозии оборудования и углеродистых сталей, изготовленных по российскому стандарту и применяемых для нефтяной и газовой промышленности, особенно для металлов, используемых для умеренных и холодных климатических условий.

Работа поддержана грантом Президента Российской Федерации для государственной поддержки молодых российских ученых - кандидатов наук (грант № MK-2251.2021.4). 


\section{Список используемых источников}

1. Afzali S., Rezaei N., Zendehboudi S. A Comprehensive Review on Enhanced Oil Recovery by Water Alternating Gas (WAG) Injection // Fuel. 2018. Vol. 227. P. 218-246. DOI: 10.1016/j.fuel.2018.04.015.

2. Al Hajeri S., Negahban S., Al-Yafei G., Al Basry A. Design and Implementation of the First CO2-EOR Pilot in Abu Dhabi, UAE // Materials of SPE EOR Conference at Oil and Gas West Asia. Muscat, Oman. 2010. Paper Number SPE-129609-MS. DOI: 10.2118/129609-ms.

3. Alagorni A.H., Yaacob Z.B., Nour A.H. An Overview of Oil Production Stages: Enhanced Oil Recovery Techniques and Nitrogen Injection // International Journal of Environmental Science and Development. 2015. Vol. 6. Issue 9. P. 693-701. DOI: 10.7763/ijesd.2015.v6.682.

4. Alderman D.H., McFarland R.M., McIntyre J.W., Minissale J.D., Roye J. Field Facilities for CO2 Tertiary Floods - a Conceptual Design // Materials of SPE Annual Technical Conference and Exhibition. New Orleans, Louisiana, USA. 1982. Paper Number SPE-11234-MS. DOI: 10.2118/11234-ms.

5. Ali A.A., Yaacob Z.B., Nour A.H. Enhanced Oil Recovery Techniques Miscible and Immiscible Flooding // Journal of Applied Sciences. 2014. Vol. 14. Issue 10. P. 1016-1022. DOI: 10.3923/jas.2014.1016.1022.

6. Al-Murayri M., Harding T.G., Maini B.B. Solubility of Methane, Nitrogen, and Carbon Dioxide in Bitumen and Water for SAGD Modelling // Journal of Canadian Petroleum Technology. 2011. Vol. 50. Issue 7. P. 34-45. Paper Number SPE-148630-PA. DOI: 10.2118/148630-PA.

7. Alston R., Kokolis G., James C. CO2 Minimum Miscibility Pressure: a Correlation for Impure CO2 Streams and Live Oil Systems // Society of Petroleum Engineers Journal. 1985. Vol. 25. Issue 2. P. 268-274. Paper Number SPE-11959PA. DOI: 10.2118/11959-PA. 
8. Bahralolom I., Orr F. Solubility and Extraction in Multiple-Contact Miscible Displacements: Comparison of N2 and CO2 Flow Visualization Experiments // SPE Reservoir Engineering. 1988. Vol. 3. Issue 1. P. 213-219. Paper Number SPE-15079-PA. DOI: 10.2118/15079-PA.

9. Bealessio B.A., Blanquez Alonso N.A., Mendes N.J., Sande A.V., Hascakir B. A Review of Enhanced Oil Recovery (EOR) Methods Applied in Kazakhstan // Petroleum. 2021. Vol. 7. Issue 1. P. 1-9. DOI: 10.1016/j.petlm.2020.03.003.

10. Beeson D., Ortloff G. Laboratory Investigation of the Water-Driven Carbon Dioxide Process for Oil Recovery // Journal of Petroleum Technology. 1959. Vol. 11. Issue 4. P. 63-66. DOI: 10.2118/1100-g.

11. Bon J., Sarma H.K., Theophilos A.M. An Investigation of Minimum Miscibility Pressure for CO2-Rich Injection Gases with Pentanes-Plus Fraction // Materials of SPE International Improved Oil Recovery Conference in Asia Pacific. Kuala Lumpur, Malaysia. 2005. Paper Number SPE-97536-MS. DOI: 10.2118/97536-ms.

12. Bougre E.S., Gamadi T.D. Enhanced Oil Recovery Application in Low Permeability Formations by the Injections of $\mathrm{CO} 2, \mathrm{~N} 2$ and $\mathrm{CO} 2 / \mathrm{N} 2$ Mixture Gases // Journal of Petroleum Exploration and Production. 2021. Vol. 11. P. 19631971. DOI: 10.1007/s13202-021-01113-5.

13. Braithwaite C. A Review of IOR/EOR Opportunities for the Brent Field: Depressurization, the Way Forward // Materials of SPE/DOE Improved Oil Recovery Symposium. Tulsa, Oklahoma, USA. 1994. Paper Number SPE-27766MS. DOI: 10.2118/27766-MS.

14. Bryant S.L., Buller D.C. Formation Damage from Acid Treatments // SPE Production Engineering. 1990. Vol. 5. Issue 4. P. 455-460. Paper Number SPE17597-PA. DOI: 10.2118/17597-PA.

15. Christiansen R.L., Haines H.K. Rapid Measurement of Minimum Miscibility Pressure with the Rising-Bubble Apparatus // SPE Reservoir Engineering. 1987. Vol. 2. Issue 4. P. 523-527. Paper Number SPE-13114-PA. DOI: 10.2118/13114-PA. 
16. Cronquist C. Carbon Dioxide Dynamic Miscibility with Light Reservoir Oils // Materials of 4th Annual US DOE Symposium. Tulsa, Oklahoma, USA. 1977.

17. DeRuiter R., Nash L., Singletary M. Solubility and Displacement Behavior of a Viscous Crude with CO2 and Hydrocarbon Gases // SPE Reservoir Engineering. 1994. Vol. 9. Issue 2. P. 101-106. SPE-20523-PA. DOI: 10.2118/20523-PA.

18. Dong M., Huang S., Dyer S.B., Mourits F.M. A Comparison of CO2 Minimum Miscibility Pressure Determinations for Weyburn Crude Oil // Journal of Petroleum Science and Engineering. 2001. Vol. 31. Issue 1. P. 13-22. DOI: 10.1016/S0920-4105(01)00135-8.

19. Emera M., Javadpour F., Sarma H. Genetic Algorithm (GA)-Based Correlations Offer More Reliable Prediction of Minimum Miscibility Pressures (MMP) between Reservoir Oil and CO2 or Flue Gas // Journal of Canadian Petroleum Technology. 2007. Vol. 46. Issue 8. Paper Number PETSOC-07-0801. DOI: 10.2118/07-08-01.

20. Farias M., Watson R. Interaction of Nitrogen/CO2 Mixtures with Crude Oil: Final Report to Department of Energy. State College: Pennsylvania State University, 2007. 43 p.

21. Gao C., Li X., Guo L., Zhao F. Heavy Oil Production by Carbon Dioxide Injection // Greenhouse Gases: Science and Technology. 2013. Vol. 3. Issue 3. P. 185-195. DOI: 10.1002/ghg.1346.

22. Gaurina-Medimurec N., Pasic B. Design and Mechanical Integrity of CO2 Injection Wells // Rudarsko-Geolosko-Naftni Zbornik. 2011. Vol. 23. P. 1-8.

23. Gharibi A., Zoveidavianpoor M. Hydraulic Fracturing for Improved Oil Recovery // Journal of Advanced Research in Fluid Mechanics and Thermal Sciences. 2015. Vol. 9. Issue 1. P. 1-18.

24. Glaso O. Generalized Minimum Miscibility Pressure Correlation (Includes Associated Papers 15845 and 16287) // Society of Petroleum Engineers Journal. 1985. Vol. 25. Issue 6. P. 927-934. Paper Number SPE-12893-PA. DOI: 10.2118/12893-PA. 
25. Hamidi H., Sharifi Haddad A., Wisdom Otumudia E., Rafati R., Mohammadian E., Azdarpour A., Tanujaya E. Recent Applications of Ultrasonic Waves in Improved Oil Recovery: A Review of Techniques and Results // Ultrasonics. 2021. Vol. 110. Article Number 106288. DOI: 10.1016/j.ultras.2020.106288.

26. Hassan A., Elkatatny S., Abdulraheem A. Intelligent Prediction of Minimum Miscibility Pressure (MMP) During CO2 Flooding Using Artificial Intelligence Techniques // Sustainability. 2019. Vol. 11. Issue 24. Article Number 7020. DOI: $10.3390 / \mathrm{su} 11247020$.

27. Hearn C.L., Whitson C.H. Evaluating Miscible and Immiscible Gas Injection in the Safah Field, Oman // Materials of SPE Reservoir Simulation Symposium. San Antonio, Texas, USA. 1995. Paper Number SPE-29115-MS. DOI: 10.2118/29115-MS.

28. Henni A., Mather A. Solubility of $\mathrm{CO}, \mathrm{NO}, \mathrm{CH}$, and $\mathrm{CH}$ in Polar Solvents // Journal of Canadian Petroleum Technology. 1999. Vol. 38. Issue 13. Paper Number PETSOC-99-13-25. DOI: 10.2118/99-13-25.

29. Holm L., Josendal V. Mechanisms of Oil Displacement by Carbon Dioxide // Journal of Petroleum Technology. 1974. Vol. 26. Issue 12. P. 14271438. Paper Number SPE-4736-PA. DOI: 10.2118/4736-PA.

30. Iwasaki S., Kamijo T., Takashina T., Tanaka H. Large Scale Flue Gas $\mathrm{CO} 2$ Recovering/CO2 Cost and Total System for CO2 Enhanced Oil Recovery // Technical Review. 2004. Vol. 41. Issue 4. P. 1-6.

31. Jia B., Tsau J., Barati R. A Review of the Current Progress of $\mathrm{CO} 2$ Injection EOR and Carbon Storage in Shale Oil Reservoirs // Fuel. 2019. Vol. 236. P. 404-427. DOI: 10.1016/j.fuel.2018.08.103.

32. Johnson J.P., Pollin J.S. Measurement and Correlation of CO2 Miscibility Pressures // Enhanced Oil Recovery: Materials of SPE/DOE Symposium. Tulsa, Oklahoma, USA. 1981. Paper Number SPE-9790-MS. DOI: 10.2118/9790-MS.

33. Lake L.W. Enhanced Oil Recovery. Hoboken: Prentice-Hall, 1989. 550 p. 
34. Linn L. CO2 Injection and Production Field Facilities Design Evaluation and Considerations // Materials of SPE Annual Technical Conference and Exhibition. Dallas, Texas, USA. 1987. Paper Number SPE-16830-MS. DOI: 10.2118/16830-MS.

35. Liu J., Sun L., Li Z., Wu X. Experimental Study on Reducing CO2-Oil Minimum Miscibility Pressure with Hydrocarbon Agents // Energies. 2019. Vol. 12. Issue 10. P. 1-17. DOI: 10.3390/en12101975.

36. Macintyre K. Design Considerations for Carbon Dioxide Injection Facilities // Journal of Canadian Petroleum Technology. 1986. Vol. 25. Issue 2. Paper Number PETSOC-86-02-09. DOI: 10.2118/86-02-09.

37. Mogensen K., Masalmeh S. A Review of EOR Techniques for Carbonate Reservoirs in Challenging Geological Settings // Journal of Petroleum Science and Engineering. 2020. Vol. 195. Article Number 107889. DOI: 10.1016/j.petrol.2020.107889.

38. Mohammadian E., Mohamed Jan B., Azdarpour A., Hamidi H., Hidayati Binti Othman N., Dollah A., Azrina Binti Sazali R. CO2-EOR/Sequestration: Current Trends and Future Horizons // Enhanced Oil Recovery Processes: New Technologies: in Book. London: IntechOpen, 2019. DOI: 10.5772/intechopen.89540.

39. Morrow N., Buckley J. Improved Oil Recovery by Low-Salinity Water Flooding // Journal of Petroleum Technology. 2011. Vol. 63. P. 106-112. Paper Number SPE-129421-JPT. DOI: 10.2118/129421-JPT.

40. Muggeridge A., Cockin A., Webb K., Frampton H., Collins I., Moulds T., Salino P. Recovery Rates, Enhanced Oil Recovery and Technological Limits // Philosophical Transactions of the Royal Society A: Mathematical, Physical And Engineering Sciences. 2014. Vol. 372. Issue 2006. Article Number 20120320. DOI: 10.1098/rsta.2012.0320. 
41. Nguyen T., Ali S.F. Effect of Nitrogen on the Solubility and Diffusivity of Carbon Dioxide into Oil and Oil Recovery by the Immiscible WAG Process // Materials of Annual Technical Meeting. Calgary, Alberta, Canada. 1995. Paper Number PETSOC-95-64. DOI: 10.2118/95-64.

42. Norouzi H., Rostami B., Khosravi M., Afra M.J. Analysis of Secondary and Tertiary High-Pressure Gas Injection at Different Miscibility Conditions: Mechanistic Study // SPE Reservoir Evaluation and Engineering. 2018. Vol. 22. Issue 1. P. 150-160. Paper Number SPE-191119-PA. DOI: 10.2118/191119-PA.

43. Nourozieh H., Kariznovi M., Abedi J. Measurement and Correlation of Solubility and Physical Properties for Gas-Saturated Athabasca Bitumen // SPE Production and Operations. 2016. Vol. 31. Issue 3. P. 207-218. Paper Number SPE-176016-PA. DOI: 10.2118/176016-PA.

44. Nunez-Lopez V., Moskal E. Potential of CO2-EOR for Near-Term Decarburization // Frontiers in Climate. 2019. Vol. 1. Issue 5. DOI: 10.3389/fclim.2019.00005.

45. Nwidee L.N., Theophilus S., Barifcani A., Sarmadivaleh M., Iglauer S. EOR Processes, Opportunities and Technological Advancements // Chemical Enhanced Oil Recovery (cEOR) - a Practical Overview: in Book. London: IntechOpen, 2016. DOI: 10.5772/64828.

46. Palasthy G., Pipicz V., Munkacsi I., Tromboczky S. Horizontal Wells in the Algyo Field, Hungary-Evaluation of a Successful IOR Project // Improved Oil Recovery: Materials of SPE/DOE Symposium. Tulsa, Oklahoma, USA. 1998. Paper Number SPE-39644-MS. DOI: 10.2118/39644-MS.

47. Rao D.N. A New Technique of Vanishing Interfacial Tension for Miscibility Determination // Fluid Phase Equilibria. 1997. Vol. 139. Issue 1-2. P. 311-324. DOI: 10.1016/s0378-3812(97)00180-5.

48. Roussanaly S., Grimstad A. The Economic Value of $\mathrm{CO} 2$ for EOR Applications // Energy Procedia. 2014. Vol. 63. P. 7836-7843. DOI: 10.1016/j.egypro.2014.11.818. 
49. Saadawi H. Surface Facilities for a CO2-EOR Project in Abu Dhabi // Oil and Gas West Asia: Materials of SPE EOR Conference. Muscat, Oman. 2010. Paper Number SPE-127765-MS. DOI: 10.2118/127765-MS.

50. Sasaki K., Sugai Y., Or C., Kono H. CO2 Solubility Characteristics of Crude Oils Related to Carbon Capture and Utilization (CCU) // G-COE Program Kyushu University Novel Carbon Resource Sciences Newsletter. 2013. Vol. 8. P. 5-8.

51. Sebastian H., Wenger R., Renner T. Correlation of Minimum Miscibility Pressure for Impure CO2 Streams // Journal of Petroleum Technology. 1985. Vol. 37. Issue 11. P. 2076-2082. Paper Number SPE-12648-PA. DOI: 10.2118/12648-PA.

52. Shafiai S.H., Gohari A. Conventional and Electrical EOR Review: the Development Trend of Ultrasonic Application in EOR // Journal of Petroleum Exploration and Production Technology. 2020. Vol. 10. Issue 7. P. 2923-2945. DOI: $10.1007 / \mathrm{s} 13202-020-00929-\mathrm{x}$.

53. Silva M., Orr F. Effect of Oil Composition on Minimum Miscibility Pressure-Part 1: Solubility of Hydrocarbons in Dense CO2 // SPE Reservoir Engineering. 1987. Vol. 2. Issue 4. P. 468-478. Paper Number SPE-14149-PA. DOI: 10.2118/14149-PA.

54. Solomon S., Flach T. 14 - Carbon Dioxide (CO2) Injection Processes and Technology // Developments and Innovation in Carbon Dioxide (CO2) Capture and Storage Technology: in Book. Cambridge: Woodhead Publishing, 2010. P. 435-466. DOI: 10.1533/9781845699574.4.435.

55. Springer S., Sadal D., Turta A. Statistical Review of the Performance of Some Horizontal Wells Drilled in IOR/EOR Projects and Gas Pools in the WCSB // Horizontal Well Technology: Materials of SPE/CIM Eighth One-Day Conference. Calgary, Alberta, Canada. 2001. Paper Number SPE-CIM-01-11MS. DOI: 10.2118/CIM-01-11-MS.

56. Sugai Y., Babadagli T., Sasaki K. Consideration of an Effect of Interfacial Area between Oil and CO2 on Oil Swelling // Journal of Petroleum Exploration and Production Technology. 2014. Vol. 4. P. 105-112. DOI: 10.1007/s13202-0130085-7. 
57. Sun Q., Retnanto A., Amani M. Seismic Vibration for Improved Oil Recovery: a Comprehensive Review of Literature // International Journal of Hydrogen Energy. 2020. Vol. 45. Issue 29. P. 14756-14778. DOI: 10.1016/j.ijhydene.2020.03.227.

58. Surguchev L., Manrique E., Alvarado V. Improved Oil Recovery: Status and Opportunities // Materials of 18th World Petroleum Congress. Johannesburg, South Africa. 2005. Paper Number WPC-18-0886. URL: https://admin.onepetro.org/WPCONGRESS/proceedings/WPC18/AllWPC18/WPC-18-0886/200977 (дата обращения: 15.08.2021).

59. Svrcek W.Y., Mehrotra A.K. Gas Solubility, Viscosity and Density Measurements for Athabasca Bitumen // Journal of Canadian Petroleum Technology. 1982. Vol. 21. Issue 4. Paper Number PETSOC-82-04-02. DOI: 10.2118/82-04-02.

60. Svrcek W.Y., Mehrotra A.K. Properties of Peace River bitumen Saturated with Field Gas Mixtures // Journal of Canadian Petroleum Technology. 1989. Vol. 28. Issue 2. Paper Number PETSOC-89-02-01. DOI: 10.2118/89-02-01.

61. Thomas S. Enhanced Oil Recovery - an Overview // Oil and Gas Science and Technology - Rev. IFP. 2008. Vol. 63. No. 1. P. 9-19. DOI: 10.2516/ogst:2007060.

62. Vali J. A Fast and Simple Method for Modeling of Oil Swelling in CO2 Injection // Geopersia. 2011. Vol. 1. Issue 2. P. 39-46. DOI: 10.22059/JGEOPE.2011.23282.

63. Vishnumolakala N., Zhang J., Ismail N.B. A Comprehensive Review of Enhanced Oil Recovery Projects in Canada and Recommendations for Planning Successful Future EOR Projects // Canada Heavy Oil: Materials of SPE Conference. Virtual. 2020. Paper Number SPE-199951-MS. DOI: 10.2118/199951-MS.

64. Wu S., Li Z., Wang Z., Sarma H.K., Zhang C., Wu M. Investigation of CO2/N2 Injection in Tight Oil Reservoirs with Confinement Effect // Energy Science and Engineering. 2020. Vol. 8. Issue 4. P. 1194-1208. DOI: 10.1002/ese3.578. 
65. Yang C., Gu Y. Diffusion Coefficients and Oil Swelling Factors of Carbon Dioxide, Methane, Ethane, Propane, and their Mixtures in Heavy Oil // Fluid Phase Equilibria. 2006. Vol. 243. Issue 1-2. P. 64-73. DOI: 10.1016/j.fluid.2006.02.020.

66. Yang C., Gu Y. A Novel Experimental Technique for Studying Solvent Mass Transfer and Oil-Swelling Effect in the Vapour Extraction (VAPEX) Process // Journal of Canadian Petroleum Technology. 2007. Vol. 46. Issue 9. Paper Number PETSOC-07-09-04. DOI: 10.2118/07-09-04.

67. Yang D., Gu Y. Visualization of Interfacial Interactions of Crude Oil-CO2 Systems Under Reservoir Conditions // Improved Oil Recovery: Materials of SPE/DOE Symposium. Tulsa, Oklahoma, USA. 2004. Paper Number SPE89366-MS. DOI: 10.2118/89366-MS.

68. Yellig W., Metcalfe R. Determination and Prediction of CO2 Minimum Miscibility Pressures (Includes Associated Paper 8876) // Journal of Petroleum Technology. 1980. Vol. 32. Issue 1. P. 160-168. Paper Number SPE-7477-PA. DOI: 10.2118/7477-PA.

69. Yuan H., Johns R., Egwuenu A., Dindoruk B. Improved MMP Correlations for CO2 Floods Using Analytical Gas Flooding Theory // Improved Oil Recovery: Materials of SPE/DOE Symposium. Tulsa, Oklahoma, USA. 2005. Paper Number SPE-89359-MS. DOI: 10.2118/89359-MS.

70. Zapivalov N. Improved Oil Recovery VS. Enhanced Oil Recovery // In Enhanced Oil Recovery - Science Topic. 2015. P. 81-93.

71. Zhang Y., Sayegh S., Huang S., Dong M. Laboratory Investigation of Enhanced Light-Oil Recovery by CO2/Flue Gas Huff-n-Puff Process // Journal of Canadian Petroleum Technology. 2006. Vol. 45. Issue 2. Paper Number PETSOC-06-02-01. DOI: 10.2118/06-02-01. 


\section{References}

1. Afzali S., Rezaei N., Zendehboudi S. A Comprehensive Review on Enhanced Oil Recovery by Water Alternating Gas (WAG) Injection. Fuel, 2018, Vol. 227, pp. 218-246. DOI: 10.1016/j.fuel.2018.04.015.

2. Al Hajeri S., Negahban S., Al-Yafei G., Al Basry A. Design and Implementation of the First CO2-EOR Pilot in Abu Dhabi, UAE. Materials of SPE EOR Conference at Oil and Gas West Asia. Muscat, Oman, 2010, Paper Number SPE-129609-MS. DOI: 10.2118/129609-ms.

3. Alagorni A.H., Yaacob Z.B., Nour A.H. An Overview of Oil Production Stages: Enhanced Oil Recovery Techniques and Nitrogen Injection. International Journal of Environmental Science and Development, 2015, Vol. 6, Issue 9, pp. 693-701. DOI: 10.7763/ijesd.2015.v6.682.

4. Alderman D.H., McFarland R.M., McIntyre J.W., Minissale J.D., Roye J. Field Facilities for CO2 Tertiary Floods - a Conceptual Design. Materials of SPE Annual Technical Conference and Exhibition. New Orleans, Louisiana, USA, 1982, Paper Number SPE-11234-MS. DOI: 10.2118/11234-ms.

5. Ali A.A., Yaacob Z.B., Nour A.H. Enhanced Oil Recovery Techniques Miscible and Immiscible Flooding. Journal of Applied Sciences, 2014, Vol. 14, Issue 10, pp. 1016-1022. DOI: 10.3923/jas.2014.1016.1022.

6. Al-Murayri M., Harding T.G., Maini B.B. Solubility of Methane, Nitrogen, and Carbon Dioxide in Bitumen and Water for SAGD Modelling. Journal of Canadian Petroleum Technology, 2011, Vol. 50, Issue 7, pp. 34-45, Paper Number SPE-148630-PA. DOI: 10.2118/148630-PA.

7. Alston R., Kokolis G., James C. CO2 Minimum Miscibility Pressure: a Correlation for Impure CO2 Streams and Live Oil Systems. Society of Petroleum Engineers Journal, 1985, Vol. 25, Issue 2, pp. 268-274, Paper Number SPE11959-PA. DOI: 10.2118/11959-PA. 
8. Bahralolom I., Orr F. Solubility and Extraction in Multiple-Contact Miscible Displacements: Comparison of N2 and CO2 Flow Visualization Experiments. SPE Reservoir Engineering, 1988, Vol. 3, Issue 1, pp. 213-219, Paper Number SPE-15079-PA. DOI: 10.2118/15079-PA.

9. Bealessio B.A., Blanquez Alonso N.A., Mendes N.J., Sande A.V., Hascakir B. A Review of Enhanced Oil Recovery (EOR) Methods Applied in Kazakhstan. Petroleum, 2021, Vol. 7, Issue 1, pp. 1-9. DOI: 10.1016/j.petlm.2020.03.003.

10. Beeson D., Ortloff G. Laboratory Investigation of the Water-Driven Carbon Dioxide Process for Oil Recovery. Journal of Petroleum Technology, 1959, Vol. 11, Issue 4, pp. 63-66. DOI: 10.2118/1100-g.l.

11. Bon J., Sarma H.K., Theophilos A.M. An Investigation of Minimum Miscibility Pressure for CO2-Rich Injection Gases with Pentanes-Plus Fraction. Materials of SPE International Improved Oil Recovery Conference in Asia Pacific. Kuala Lumpur, Malaysia, 2005, Paper Number SPE-97536-MS. DOI: 10.2118/97536-ms.

12. Bougre E.S., Gamadi T.D. Enhanced Oil Recovery Application in Low Permeability Formations by the Injections of $\mathrm{CO} 2, \mathrm{~N} 2$ and $\mathrm{CO} 2 / \mathrm{N} 2$ Mixture Gases. Journal of Petroleum Exploration and Production, 2021, Vol. 11, pp. 1963-1971. DOI: 10.1007/s13202-021-01113-5.

13. Braithwaite C. A Review of IOR/EOR Opportunities for the Brent Field: Depressurization, the Way Forward. Materials of SPE/DOE Improved Oil Recovery Symposium. Tulsa, Oklahoma, USA, 1994, Paper Number SPE-27766MS. DOI: 10.2118/27766-MS.

14. Bryant S.L., Buller D.C. Formation Damage from Acid Treatments. SPE Production Engineering, 1990, Vol. 5, Issue 4, pp. 455-460, Paper Number SPE17597-PA. DOI: 10.2118/17597-PA.

15. Christiansen R.L., Haines H.K. Rapid Measurement of Minimum Miscibility Pressure with the Rising-Bubble Apparatus. SPE Reservoir Engineering, 1987, Vol. 2, Issue 4, pp. 523-527, Paper Number SPE-13114-PA. DOI: 10.2118/13114-PA. 
16. Cronquist C. Carbon Dioxide Dynamic Miscibility with Light Reservoir Oils. Materials of 4th Annual US DOE Symposium. Tulsa, Oklahoma, USA, 1977.

17. DeRuiter R., Nash L., Singletary M. Solubility and Displacement Behavior of a Viscous Crude with $\mathrm{CO} 2$ and Hydrocarbon Gases. SPE Reservoir Engineering, 1994, Vol. 9, Issue 2, pp. 101-106, SPE-20523-PA. DOI: 10.2118/20523-PA.

18. Dong M., Huang S., Dyer S.B., Mourits F.M. A Comparison of CO2 Minimum Miscibility Pressure Determinations for Weyburn Crude Oil. Journal of Petroleum Science and Engineering, 2001, Vol. 31, Issue 1, pp. 13-22. DOI: 10.1016/S0920-4105(01)00135-8.

19. Emera M., Javadpour F., Sarma H. Genetic Algorithm (GA)-Based Correlations Offer More Reliable Prediction of Minimum Miscibility Pressures (MMP) between Reservoir Oil and $\mathrm{CO} 2$ or Flue Gas. Journal of Canadian Petroleum Technology, 2007, Vol. 46, Issue 8, Paper Number PETSOC-07-0801. DOI: 10.2118/07-08-01.

20. Farias M., Watson R. Interaction of Nitrogen/CO2 Mixtures with Crude Oil: Final Report to Department of Energy. State College, Pennsylvania State University, 2007. 43 p.

21. Gao C., Li X., Guo L., Zhao F. Heavy Oil Production by Carbon Dioxide Injection. Greenhouse Gases: Science and Technology, 2013, Vol. 3, Issue 3, pp. 185-195. DOI: 10.1002/ghg.1346.

22. Gaurina-Medimurec N., Pasic B. Design and Mechanical Integrity of CO2 Injection Wells. Rudarsko-Geolosko-Naftni Zbornik, 2011, Vol. 23, pp. 1-8.

23. Gharibi A., Zoveidavianpoor M. Hydraulic Fracturing for Improved Oil Recovery. Journal of Advanced Research in Fluid Mechanics and Thermal Sciences, 2015, Vol. 9, Issue 1, pp. 1-18.

24. Glaso O. Generalized Minimum Miscibility Pressure Correlation (Includes Associated Papers 15845 and 16287). Society of Petroleum Engineers Journal, 1985, Vol. 25, Issue 6, pp. 927-934, Paper Number SPE-12893-PA. DOI: 10.2118/12893-PA. 
25. Hamidi H., Sharifi Haddad A., Wisdom Otumudia E., Rafati R., Mohammadian E., Azdarpour A., Tanujaya E. Recent Applications of Ultrasonic Waves in Improved Oil Recovery: A Review of Techniques and Results. Ultrasonics, 2021, Vol. 110, Article Number 106288. DOI: 10.1016/j.ultras.2020.106288.

26. Hassan A., Elkatatny S., Abdulraheem A. Intelligent Prediction of Minimum Miscibility Pressure (MMP) During CO2 Flooding Using Artificial Intelligence Techniques. Sustainability, 2019, Vol. 11, Issue 24, Article Number 7020. DOI: $10.3390 / \mathrm{su} 11247020$.

27. Hearn C.L., Whitson C.H. Evaluating Miscible and Immiscible Gas Injection in the Safah Field, Oman. Materials of SPE Reservoir Simulation Symposium. San Antonio, Texas, USA, 1995, Paper Number SPE-29115-MS. DOI: 10.2118/29115-MS.

28. Henni A., Mather A. Solubility of $\mathrm{CO}, \mathrm{NO}, \mathrm{CH}$, and $\mathrm{CH}$ in Polar Solvents. Journal of Canadian Petroleum Technology, 1999, Vol. 38, Issue 13, Paper Number PETSOC-99-13-25. DOI: 10.2118/99-13-25.

29. Holm L., Josendal V. Mechanisms of Oil Displacement by Carbon Dioxide. Journal of Petroleum Technology, 1974, Vol. 26, Issue 12, pp. 14271438. Paper Number SPE-4736-PA. DOI: 10.2118/4736-PA.

30. Iwasaki S., Kamijo T., Takashina T., Tanaka H. Large Scale Flue Gas $\mathrm{CO} 2$ Recovering/CO2 Cost and Total System for CO2 Enhanced Oil Recovery. Technical Review, 2004, Vol. 41, Issue 4, pp. 1-6.

31. Jia B., Tsau J., Barati R. A Review of the Current Progress of CO2 Injection EOR and Carbon Storage in Shale Oil Reservoirs. Fuel, 2019, Vol. 236, pp. 404-427. DOI: 10.1016/j.fuel.2018.08.103.

32. Johnson J.P., Pollin J.S. Measurement and Correlation of CO2 Miscibility Pressures. Materials of SPE/DOE Symposium «Enhanced Oil Recovery». Tulsa, Oklahoma, USA, 1981, Paper Number SPE-9790-MS. DOI: 10.2118/9790-MS.

33. Lake L.W. Enhanced Oil Recovery. Hoboken, Prentice-Hall, 1989. 550 p. 
34. Linn L. CO2 Injection and Production Field Facilities Design Evaluation and Considerations. Materials of SPE Annual Technical Conference and Exhibition. Dallas, Texas, USA, 1987, Paper Number SPE-16830-MS. DOI: 10.2118/16830-MS.

35. Liu J., Sun L., Li Z., Wu X. Experimental Study on Reducing CO2-Oil Minimum Miscibility Pressure with Hydrocarbon Agents. Energies, 2019, Vol. 12, Issue 10, pp. 1-17. DOI: 10.3390/en12101975.

36. Macintyre K. Design Considerations for Carbon Dioxide Injection Facilities. Journal of Canadian Petroleum Technology, 1986, Vol. 25, Issue 2, Paper Number PETSOC-86-02-09. DOI: 10.2118/86-02-09.

37. Mogensen K., Masalmeh S. A Review of EOR Techniques for Carbonate Reservoirs in Challenging Geological Settings. Journal of Petroleum Science and Engineering, 2020, Vol. 195, Article Number 107889. DOI: 10.1016/j.petrol.2020.107889.

38. Mohammadian E., Mohamed Jan B., Azdarpour A., Hamidi H., Hidayati Binti Othman N., Dollah A., Azrina Binti Sazali R. CO2-EOR/Sequestration: Current Trends and Future Horizons. In Book «Enhanced Oil Recovery Processes: New Technologies». London, IntechOpen, 2019. DOI: 10.5772/intechopen.89540.

39. Morrow N., Buckley J. Improved Oil Recovery by Low-Salinity Water Flooding. Journal of Petroleum Technology, 2011, Vol. 63, pp. 106-112, Paper Number SPE-129421-JPT. DOI: 10.2118/129421-JPT.

40. Muggeridge A., Cockin A., Webb K., Frampton H., Collins I., Moulds T., Salino P. Recovery Rates, Enhanced Oil Recovery and Technological Limits. Philosophical Transactions of the Royal Society A: Mathematical, Physical And Engineering Sciences, 2014. Vol. 372, Issue 2006, Article Number 20120320. DOI: 10.1098/rsta.2012.0320.

41. Nguyen T., Ali S.F. Effect of Nitrogen on the Solubility and Diffusivity of Carbon Dioxide into Oil and Oil Recovery by the Immiscible WAG Process. Materials of Annual Technical Meeting. Calgary, Alberta, Canada, 1995, Paper Number PETSOC-95-64. DOI: 10.2118/95-64. 
42. Norouzi H., Rostami B., Khosravi M., Afra M.J. Analysis of Secondary and Tertiary High-Pressure Gas Injection at Different Miscibility Conditions: Mechanistic Study. SPE Reservoir Evaluation and Engineering, 2018, Vol. 22, Issue 1, pp. 150-160, Paper Number SPE-191119-PA. DOI: 10.2118/191119-PA.

43. Nourozieh H., Kariznovi M., Abedi J. Measurement and Correlation of Solubility and Physical Properties for Gas-Saturated Athabasca Bitumen. SPE Production and Operations, 2016, Vol. 31, Issue 3, pp. 207-218, Paper Number SPE-176016-PA. DOI: 10.2118/176016-PA.

44. Nunez-Lopez V., Moskal E. Potential of CO2-EOR for Near-Term Decarburization. Frontiers in Climate, 2019, Vol. 1, Issue 5. DOI: 10.3389/fclim.2019.00005.

45. Nwidee L.N., Theophilus S., Barifcani A., Sarmadivaleh M., Iglauer S. EOR Processes, Opportunities and Technological Advancements. In Book «Chemical Enhanced Oil Recovery (cEOR) - a Practical Overview». London, IntechOpen, 2016. DOI: 10.5772/64828.

46. Palasthy G., Pipicz V., Munkacsi I., Tromboczky S. Horizontal Wells in the Algyo Field, Hungary-Evaluation of a Successful IOR Project. Materials of SPE/DOE Symposium «Improved Oil Recovery». Tulsa, Oklahoma, USA, 1998, Paper Number SPE-39644-MS. DOI: 10.2118/39644-MS.

47. Rao D.N. A New Technique of Vanishing Interfacial Tension for Miscibility Determination. Fluid Phase Equilibria, 1997, Vol. 139, Issue 1-2, pp. 311-324. DOI: 10.1016/s0378-3812(97)00180-5.

48. Roussanaly S., Grimstad A. The Economic Value of $\mathrm{CO} 2$ for EOR Applications. Energy Procedia, 2014, Vol. 63, pp. 7836-7843. DOI: 10.1016/j.egypro.2014.11.818.

49. Saadawi H. Surface Facilities for a CO2-EOR Project in Abu Dhabi. Materials of SPE EOR Conference "Oil and Gas West Asia». Muscat, Oman, 2010, Paper Number SPE-127765-MS. DOI: 10.2118/127765-MS. 
50. Sasaki K., Sugai Y., Or C., Kono H. CO2 Solubility Characteristics of Crude Oils Related to Carbon Capture and Utilization (CCU). G-COE Program Kyushu University Novel Carbon Resource Sciences Newsletter, 2013, Vol. 8, pp. 5-8.

51. Sebastian H., Wenger R., Renner T. Correlation of Minimum Miscibility Pressure for Impure CO2 Streams. Journal of Petroleum Technology, 1985, Vol. 37, Issue 11, pp. 2076-2082, Paper Number SPE-12648-PA. DOI: 10.2118/12648-PA.

52. Shafiai S.H., Gohari A. Conventional and Electrical EOR Review: the Development Trend of Ultrasonic Application in EOR. Journal of Petroleum Exploration and Production Technology, 2020, Vol. 10, Issue 7, pp. 2923-2945. DOI: 10.1007/s13202-020-00929-x.

53. Silva M., Orr F. Effect of Oil Composition on Minimum Miscibility Pressure-Part 1: Solubility of Hydrocarbons in Dense CO2. SPE Reservoir Engineering, 1987, Vol. 2, Issue 4, pp. 468-478, Paper Number SPE-14149-PA. DOI: 10.2118/14149-PA.

54. Solomon S., Flach T. 14 - Carbon Dioxide (CO2) Injection Processes and Technology. In Book «Developments and Innovation in Carbon Dioxide (CO2) Capture and Storage Technology». Cambridge, Woodhead Publishing, 2010. pp. 435-466. DOI: 10.1533/9781845699574.4.435.

55. Springer S., Sadal D., Turta A. Statistical Review of the Performance of Some Horizontal Wells Drilled in IOR/EOR Projects and Gas Pools in the WCSB. Materials of SPE/CIM Eighth One-Day Conference "Horizontal Well Technology». Calgary, Alberta, Canada, 2001, Paper Number SPE-CIM-01-11MS. DOI: 10.2118/CIM-01-11-MS.

56. Sugai Y., Babadagli T., Sasaki K. Consideration of an Effect of Interfacial Area between Oil and CO2 on Oil Swelling. Journal of Petroleum Exploration and Production Technology, 2014, Vol. 4, pp. 105-112. DOI: 10.1007/s13202-013-0085-7.

57. Sun Q., Retnanto A., Amani M. Seismic Vibration for Improved Oil Recovery: a Comprehensive Review of Literature. International Journal of Hydrogen Energy, 2020, Vol. 45, Issue 29, pp. 14756-14778. DOI: 10.1016/j.ijhydene.2020.03.227. 
58. Surguchev L., Manrique E., Alvarado V. Improved Oil Recovery: Status and Opportunities. Materials of 18th World Petroleum Congress. Johannesburg, South Africa, 2005, Paper Number WPC-18-0886. Available at: https://admin.onepetro.org/WPCONGRESS/proceedings/WPC18/AllWPC18/WPC-18-0886/200977 (accessed 15.08.2021).

59. Svrcek W.Y., Mehrotra A.K. Gas Solubility, Viscosity and Density Measurements for Athabasca Bitumen. Journal of Canadian Petroleum Technology, 1982, Vol. 21, Issue 4, Paper Number PETSOC-82-04-02. DOI: 10.2118/82-04-02.

60. Svrcek W.Y., Mehrotra A.K. Properties of Peace River bitumen Saturated with Field Gas Mixtures. Journal of Canadian Petroleum Technology, 1989, Vol. 28, Issue 2, Paper Number PETSOC-89-02-01. DOI: 10.2118/89-02-01.

61. Thomas S. Enhanced Oil Recovery - an Overview. Oil and Gas Science and Technology - Rev. IFP, 2008, Vol. 63, No. 1, pp. 9-19. DOI: 10.2516/ogst:2007060.

62. Vali J. A Fast and Simple Method for Modeling of Oil Swelling in CO2 Injection. Geopersia, 2011, Vol. 1, Issue 2, pp. 39-46. DOI: 10.22059/JGEOPE.2011.23282.

63. Vishnumolakala N., Zhang J., Ismail N.B. A Comprehensive Review of Enhanced Oil Recovery Projects in Canada and Recommendations for Planning Successful Future EOR Projects. Materials of SPE Conference «Canada Heavy Oil». Virtual, 2020, Paper Number SPE-199951-MS. DOI: 10.2118/199951-MS.

64. Wu S., Li Z., Wang Z., Sarma H.K., Zhang C., Wu M. Investigation of CO2/N2 Injection in Tight Oil Reservoirs with Confinement Effect. Energy Science and Engineering, 2020, Vol. 8, Issue 4, pp. 1194-1208. DOI: 10.1002/ese3.578.

65. Yang C., Gu Y. Diffusion Coefficients and Oil Swelling Factors of Carbon Dioxide, Methane, Ethane, Propane, and their Mixtures in Heavy Oil. Fluid Phase Equilibria, 2006, Vol. 243, Issue 1-2, pp. 64-73. DOI: 10.1016/j.fluid.2006.02.020. 
66. Yang C., Gu Y. A Novel Experimental Technique for Studying Solvent Mass Transfer and Oil-Swelling Effect in the Vapour Extraction (VAPEX) Process. Journal of Canadian Petroleum Technology, 2007, Vol. 46, Issue 9, Paper Number PETSOC-07-09-04. DOI: 10.2118/07-09-04.

67. Yang D., Gu Y. Visualization of Interfacial Interactions of Crude Oil-CO2 Systems Under Reservoir Conditions. Materials of SPE/DOE Symposium «Improved Oil Recovery». Tulsa, Oklahoma, USA, 2004, Paper Number SPE89366-MS. DOI: 10.2118/89366-MS.

68. Yellig W., Metcalfe R. Determination and Prediction of CO2 Minimum Miscibility Pressures (Includes Associated Paper 8876). Journal of Petroleum Technology, 1980, Vol. 32, Issue 1, pp. 160-168, Paper Number SPE-7477-PA. DOI: 10.2118/7477-PA.

69. Yuan H., Johns R., Egwuenu A., Dindoruk B. Improved MMP Correlations for CO2 Floods Using Analytical Gas Flooding Theory. Materials of SPE/DOE Symposium «Improved Oil Recovery». Tulsa, Oklahoma, USA, 2005, Paper Number SPE-89359-MS. DOI: 10.2118/89359-MS.

70. Zapivalov N. Improved Oil Recovery VS. Enhanced Oil Recovery. In Enhanced Oil Recovery - Science Topic. 2015. pp. 81-93.

71. Zhang Y., Sayegh S., Huang S., Dong M. Laboratory Investigation of Enhanced Light-Oil Recovery by CO2/Flue Gas Huff-n-Puff Process. Journal of Canadian Petroleum Technology, 2006, Vol. 45, Issue 2, Paper Number PETSOC-06-02-01. DOI: 10.2118/06-02-01. 


\section{Сведения об авторах}

\section{About the authors}

Павлова Прасковья Леонидовна, канд. техн. наук, доцент кафедры машин и оборудования нефтяных и газовых промыслов, Сибирский федеральный университет, г. Красноярск, Российская Федерация

Praskovya L. Pavlova, Candidate of Engineering Sciences, Assistant Professor of Machinery and Equipment of Oil and Gas Fields Department, Siberian Federal University, Krasnoyarsk, Russian Federation

e-mail: ppavlova@sfu-kras.ru

Михиенкова Евгения Игоревна, старший преподаватель кафедры бурения нефтяных и газовых скважин, Сибирский федеральный университет, г. Красноярск, Российская Федерация

Evgeniya I. Mikhienkova, Senior Lecturer of Oil and Gas Well Drilling Department, Siberian Federal University, Krasnoyarsk, Russian Federation e-mail: emikhienkova@sfu-kras.ru 